Proc. Indian Acad. Sci. (Chem. Sci.), Vol. 107, No. 5, October 1995, pp. 573-580.

(1) Printed in India.

\title{
Investigations on sodium tin phosphate and tin pyrophosphate glasses
}

\author{
K C SOBHA and K J RAO* \\ Materials Research Centre, Indian Institute of Science, Bangalore 560012, India \\ MS received 16 June 1995
}

\begin{abstract}
Glasses of the alkali tin phosphate system have been investigated. The infrared absorption and fluorescence spectra of the glasses have been examined. It is found that tin is present in both +2 and +4 oxidation states. Also tin ions occupy four- or six-coordinated sites in the glass.
\end{abstract}

Keywords. Tin glasses; tin pyrophosphate; NASICON; flame melting.

\section{Introduction}

Tin oxides are special constituents of commercial glasses, added mainly to improve the stability of the glasses (Tick 1984; Music et al 1991). But reported studies on glasses with tin oxide ( $\mathrm{SnO}$ or $\mathrm{SnO}_{2}$ ) as the main constituent are rather few. From the Mössbauer study of the ${ }^{119} \mathrm{Sn}$ nucleus (Evtrop'ev et al 1970), it has been found that $\mathrm{Sn}$ is present mainly as $\mathrm{Sn}^{4+}$ ions in silicate and borate glasses whereas it is present only as $\mathrm{Sn}^{2+}$ ions in phosphate glasses. The compound sodium tin phosphate $\mathrm{NaSn}_{2}\left(\mathrm{PO}_{4}\right)$, which is a NASICON-type material (NASICON is the acronym for Na-Super ionic conductor, based on $\mathrm{NaZr}_{2}\left(\mathrm{PO}_{4}\right)_{3}$ (Goodenough et al 1976, Alamo and Roy 1986)) forms a glass when melted in a graphite crucible using an oxy-butane flame. In this paper we present the results of our investigations on some alkali tin phosphate glasses and tin pyrophosphate glass prepared using the above method.

\section{Experimental}

Crystalline $\mathrm{NaSn}_{2}\left(\mathrm{PO}_{4}\right)_{3}$ was prepared from Analar Grade $\mathrm{Na}_{2} \mathrm{CO}_{3}, \mathrm{SnO}_{2}$ and diammonium hydrogen phosphate. The reactants were mixed thoroughly and heated to $573 \mathrm{~K}$ to decompose the diammonium hydrogen phosphate. The mixture was again ground and heated at 1073 and $1273 \mathrm{~K}$ for $12 \mathrm{~h}$ each with intermittent grinding. A similar procedure was adopted to make compositions of $\mathrm{LiSn}_{2}\left(\mathrm{PO}_{4}\right)_{3}$ and $\mathrm{KSn}_{2}\left(\mathrm{PO}_{4}\right)_{3}$. These compositions were melted in graphite crucibles by directly contacting an oxy-butane flame. Drops of the melt were quenched into glass between stainless steel plates. The batches melt incongruently with loss of material, but ultimately result in a good glass-forming melt. The NSP glass pieces (obtained from $\mathrm{NaSn}_{2}\left(\mathrm{PO}_{4}\right)_{3}$ ) were powdered and mixed with $\mathrm{NaPO}_{3}$ glass powder (which had been initially made by melting $\mathrm{NaPO}_{3}$ in an electric furnace at $1173 \mathrm{~K}$ ) and the batches were again melted using the flame and quenched into glasses. For preparing the tin pyrophosphate, appropriate amounts of $\mathrm{SnO}$ and $\left(\mathrm{NH}_{4}\right)_{2} \mathrm{H}\left(\mathrm{PO}_{4}\right)$ were mixed and

* For correspondence 
heated at $573 \mathrm{~K}(5 \mathrm{~h})$, ground and heated at $1073 \mathrm{~K}(10 \mathrm{~h})$. The batch was then melted using the flame and quenched. Compositions were analysed using an EDAX-AN$10000 \mathrm{X}$-ray analyser attached to an S-360 Cambridge scanning electron microscope. The glass transition temperature $\left(T_{g}\right)$ and the heat capacities $\left(C_{p}\right.$ 's) were determined using a Perkin-Elmer DSC-2 Differential Scanning Calorimeter. Dry nitrogen was used as purge gas. $T_{g}$ was determined from a $20 \mathrm{~K} / \mathrm{min}$ scan. For the specific heat determination, the NSP sample was first annealed at temperatures about $20 \mathrm{~K}$ below $T_{g}$ and scans for the specific heat measurements were carried out at $10 \mathrm{~K} / \mathrm{min}$. Single crystalline sapphire was used as standard for $C_{p}$ measurement. The infrared transmission spectra were recorded from 4000 to $200 \mathrm{~cm}^{-1}$ using a Perkin-Elmer 580 double beam IR spectrometer using pellets of the glass powder with $\mathrm{KBr}$. The Fourier Transform IR (FTIR) spectra were recorded using a Bruker IFS 113 FTIR spectrometer. Pellets of the glass powder in polyethylene were used for recording the FTIR spectra. The fluorescence excitation and emission spectra were recorded using a Shimadzu spectrofluorophotometer Model RF-510 and a 150W xenon lamp. Band widths for both excitation and emission were $10 \mathrm{~nm}$.

\section{Results and discussion}

The energy dispersive X-ray analysis (EDAX) patterns for $\mathrm{Sn}_{2}\left(\mathrm{PO}_{4}\right)_{3}$ compound and the glass obtained by melting it (NSP) and quenching are given in figure 1. EDAX was not accurate for analysing $\mathrm{Na}$ and hence it could not be determined. The EDAX for the glass gave a proportion of $\mathrm{Sn}: \mathrm{P}=52: 48$ which clearly shows enrichment of glass composition with respect to $\mathrm{Sn}$. In fact it is almost the composition of pyrophosphate glass. Tin pyrophosphate glass showed $\mathrm{Sn}$ :P ratio of 53:47 suggesting very little loss of components from the glass during melting. Glasses have been prepared based on NSP glass itself as one of the constituents with $\mathrm{NaPO}_{3}$ (NP) as the other constituent. Several binary NSP-NP glasses have been examined in this system. A glass containing some added $\mathrm{SnO}_{2}$ (which readily dissolves in molten NSP) has also been studied. Various glass compositions are listed in table 1.

The $T_{g}$ values for the $\mathrm{Li}, \mathrm{Na}$ and $\mathrm{K}$ containing glasses (designated as LSP, NSP and KSP glasses respectively) estimated from the DSC were found to be very close $(525,529$ and $530 \mathrm{~K}$ respectively). The specific heat variation of the NSP glass is shown in figure 2. Molar heat capacities have not been calculated in view of the compositional uncertainty and even possible contamination with carbon from the graphite crucible.

The infrared spectra of LSP, NSP and KSP glasses are shown in figure 3, along with that of crystalline $\mathrm{NaSn}_{2}\left(\mathrm{PO}_{4}\right)_{3}$. The change in composition is reflected in the spectra. The infrared spectrum of $\operatorname{Sn}_{2} \mathrm{P}_{2} \mathrm{O}_{7}$ glass is shown in figure 4, along with that of $\mathrm{Pb}_{2} \mathrm{P}_{2} \mathrm{O}_{7}$ glass (taken from Ananthraj 1991).

The $T_{g}$ of $\mathrm{Sn}_{2} \mathrm{P}_{2} \mathrm{O}_{7}$ glass is $525 \mathrm{~K}$ while the reported value of $T_{g}$ of $\mathrm{Pb}_{2} \mathrm{P}_{2} \mathrm{O}_{7}$ is $638 \mathrm{~K}$ (Ananthraj 1991). The similarity of the IR spectra of the two pyrophosphate glasses is striking. The IR spectra of $\mathrm{Sn}_{2} \mathrm{P}_{2} \mathrm{O}_{7}$ and $\mathrm{Pb}_{2} \mathrm{P}_{2} \mathrm{O}_{7}$ glasses are almost identical. The $\mathrm{Pb}_{2} \mathrm{P}_{2} \mathrm{O}_{7}$ glass has been studied by Ananthraj et al (1991) and it is found that, in addition to the pyrophosphate units, rings of phosphate tetrahedra and isolated $\left[\mathrm{PO}_{4}\right]^{3-}$ ions are also present in the glass, which are produced through the structural disproportionation given below

$$
2 \mathrm{P}_{2} \mathrm{O}_{7}^{4-} \rightleftharpoons \mathrm{PO}_{4}^{3-}+\mathrm{P}_{3} \mathrm{O}_{10}^{5-}
$$




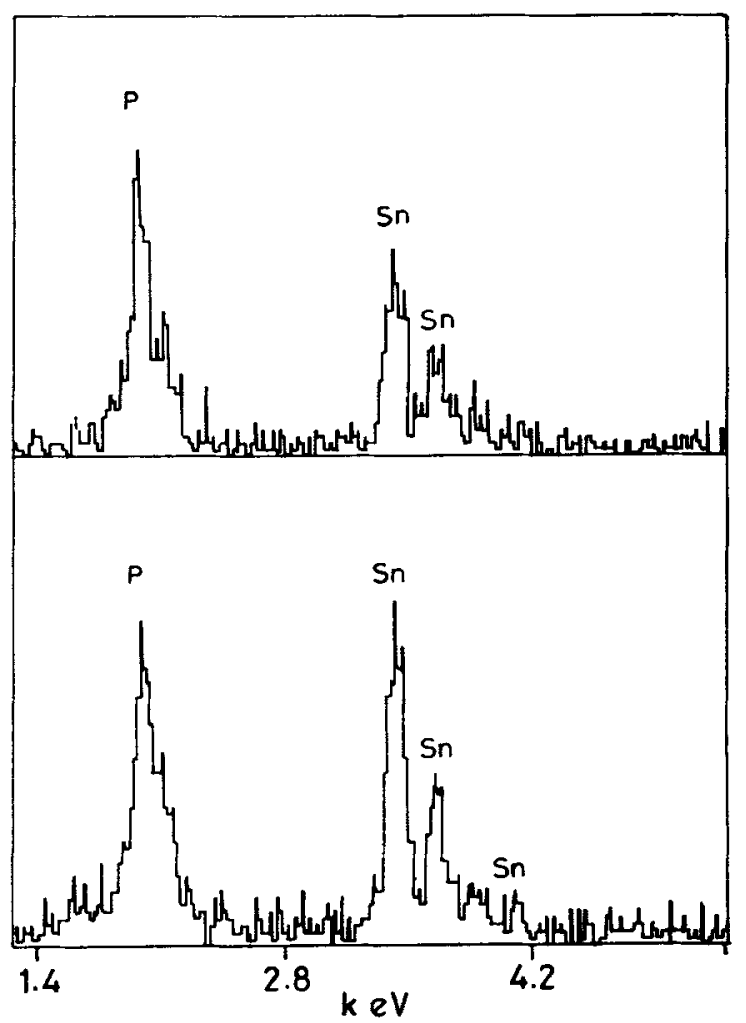

Figure 1. X-ray energy dispersive analysis (EDAX) patterns of crystalline $\mathrm{NaSn}_{2}\left(\mathrm{PO}_{4}\right)_{3}$ and the NSP glass.

Table 1. Glass composition and glass transition temperatures $\left(T_{g}\right)$ of the glasses in the $\mathrm{NSP}-\mathrm{NP}-\mathrm{SnO}_{2}$ system.

\begin{tabular}{llc}
\hline & $\begin{array}{c}\text { Composition } \\
\text { NSP, NP, SnO }\end{array}$ & $\begin{array}{c}T_{g} \\
\text { (weight \%) }\end{array}$ \\
\hline No. & $0 \cdot 8,0,0 \cdot 2$ & 560 \\
\hline 1 & $1,0,0$ & 529 \\
2 & $0 \cdot 8,0 \cdot 2,0$ & 522 \\
3 & $0 \cdot 6,0 \cdot 4,0$ & 527 \\
4 & $0 \cdot 4,0 \cdot 6,0$ & 531 \\
5 & $0 \cdot 2,0 \cdot 8,0$ & 539 \\
6 & $0,1,0$ & 566 \\
7 &
\end{tabular}

or in general

$$
2 \mathrm{P}_{n} \mathrm{O}_{3 n+1}^{(n+2)-} \rightleftharpoons \mathrm{P}_{n-1} \mathrm{O}_{3(n-1)+1}^{[(n-1)+2]}+\mathrm{P}_{n+1} \mathrm{O}_{3(n+1)+1}^{[(n+1)+2]-}
$$

The $717 \mathrm{~cm}^{-1}$ band has been attributed to $\mathrm{P}-\mathrm{O}-\mathrm{P}$ bending vibrations from ring structures and the shoulder at $1100 \mathrm{~cm}^{-1}$ to orthophosphate ions. Similar assignments 


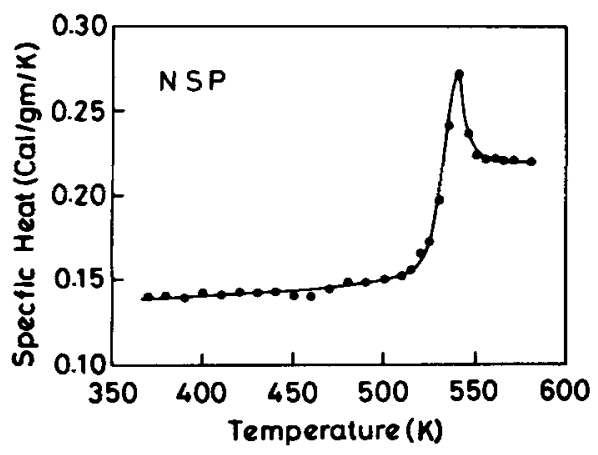

Figure 2. Specific heat variation of the NSP glass with temperature.

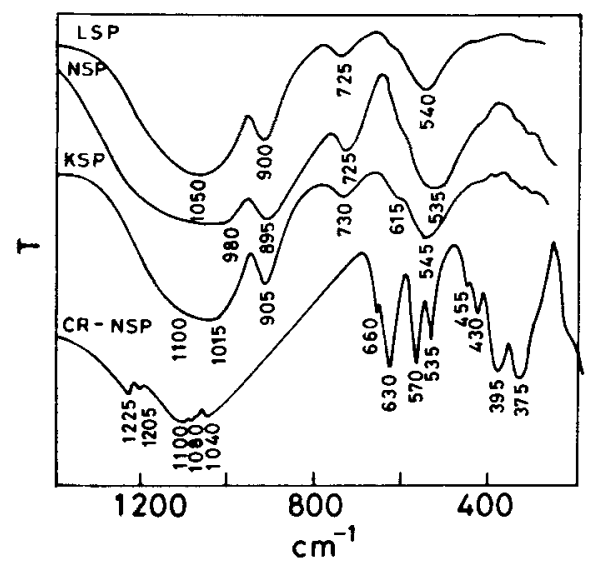

Figure 3. Infrared spectra of LSP, NSP and KSP glasses and crystalline $\mathrm{NaSn}_{2}\left(\mathrm{PO}_{4}\right)_{3}(\mathrm{CR}-\mathrm{NSP})$.

hold good for the tin pyrophosphate glass also, and we may conclude that the behaviour of tin is exactly similar to that of lead in glasses. Presence of lead in four- as well as six-coordinated positions has been established in many glasses (Damodaran et al 1988; Selvaraj and Rao 1988; Ananthraj 1991). The shoulder at $1150 \mathrm{~cm}^{-1}$ and $910 \mathrm{~cm}^{-1}$ indicate the presence of pyrophosphate units as found in our IR study on glasses with NASICON chemistry (Sobha and Rao 1995) as well as the crystalline pyrophosphates investigated by Ananthraj et al (1986) and Ananthraj (1991).

The $T_{g}$ values obtained for the various NSP-NP glass compositions are tabulated in table 1 . Highest $T_{g}$ is exhibited by the $\mathrm{NaPO}_{3}$ glass. However, the spread of $T_{g}$ itself is very narrow. Addition of $\mathrm{SnO}_{2}$ also increases the $T_{g}$ of NSP glass. The $T_{g}$ of NSP glass appears to be between that of $\mathrm{Sn}_{2} \mathrm{P}_{2} \mathrm{O}_{7}$ and $\mathrm{NaPO}_{3}$ glasses.

Given in figure 5 are the IR absorption spectra of the above glasses. The spectra suggest that as $\mathrm{NaPO}_{3}$ content increases, peaks corresponding to the metaphosphate $\left(1270 \mathrm{~cm}^{-1}\right.$ of $\mathrm{P}=\mathrm{O}$ (Corbridge and Lowe 1954; Osaka et al 1984)) and $525 \mathrm{~cm}^{-1}$ (-O- P-O bending mode in $\left[\mathrm{POO}_{2 / 2} \mathrm{O}\right]^{-}$tetrahedra (Osaka et al 1984)) also increase. In the pure NSP glass the absorption band at $1270 \mathrm{~cm}^{-1}$ band is merged into the shoulder. In the excess $\mathrm{SnO}_{2}$ composition, the $985 \mathrm{~cm}^{-1}$ band, barely identifiable in 


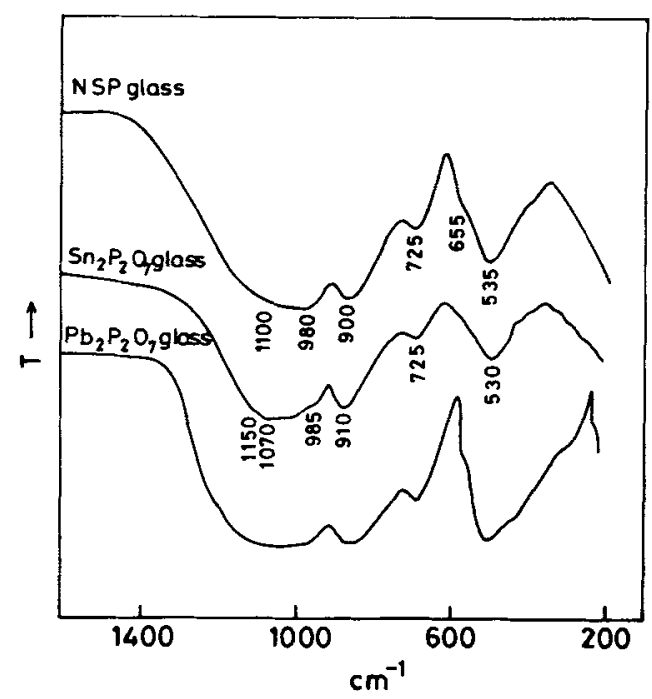

Figure 4. Infrared spectra of NSP glass and $\mathrm{Sn}_{2} \mathrm{P}_{2} \mathrm{O}_{7}$ glass along with that of $\mathrm{Pb}_{2} \mathrm{P}_{2} \mathrm{O}_{7}$ glass (taken from Ananthraj 1991).

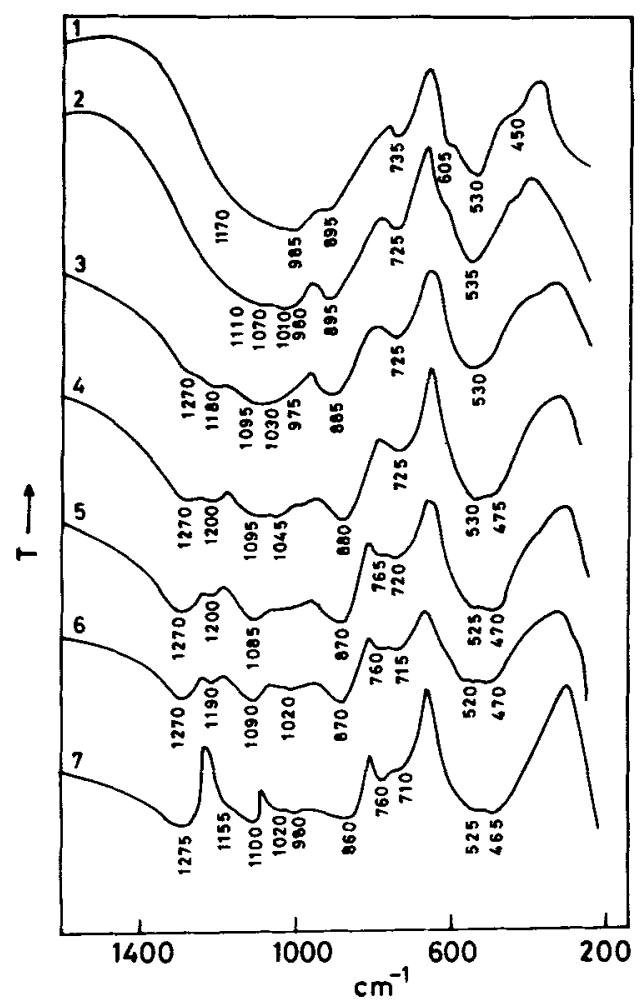

Figure 5. IR absorption spectra of the glasses in the NSP-NP-SnO $\mathrm{O}_{2}$ system. The numbering of the glasses is the same as in table 1. 


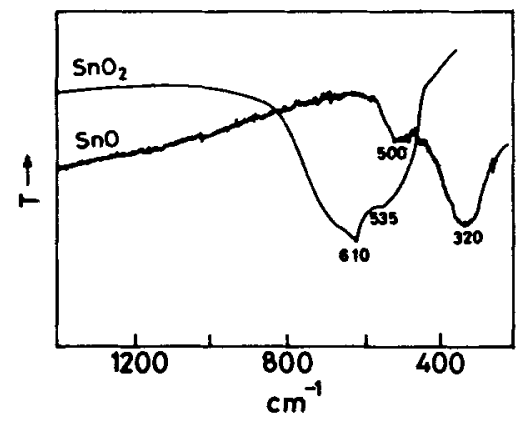

Figure 6. IR absorption spectra of $\mathrm{SnO}_{2}$ and $\mathrm{SnO}$.

pure NSP glass, becomes clearly identifiable. The enhanced intensity of the $985 \mathrm{~cm}^{-1}$ compared to the low NP glasses suggests that this peak may be assigned to $\mathrm{Sn}-\mathrm{O}-\mathrm{P}$ linkages associated with tin in $\mathrm{Sn}^{4+}$ state. Similarly, the shoulder at $605 \mathrm{~cm}^{-1}$ in the NSP glass spectrum appears as a more prominent peak at $605 \mathrm{~cm}^{-1}$ in the $\left(\mathrm{NSP}+\mathrm{SnO}_{2}\right)$ glass spectrum. This can be assigned to $\mathrm{Sn}^{4+}$ in six-coordination (Wyckoff 1971) on comparison with the spectrum of pure $\mathrm{SnO}_{2}$ itself given in figure 6. Thus, both $\mathrm{Sn}^{4+}$ and $\mathrm{Sn}^{2+}$ appear to be present in pure NSP glass.

The features in the IR spectra of NSP glass look more like a combination of the spectra of $\mathrm{Sn}_{2} \mathrm{P}_{2} \mathrm{O}_{7}$ and NP glasses (figures 4 and 5). In fact, the preparation of NSP

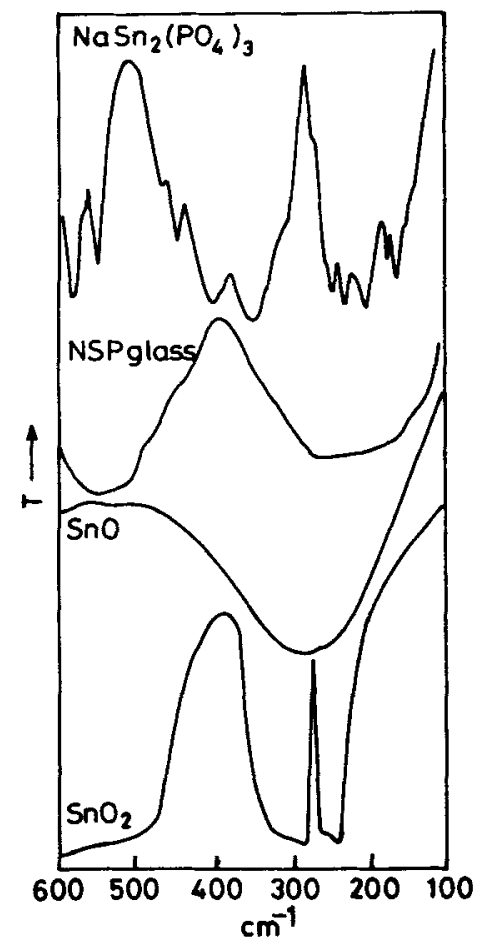

Figure 7. FTIR spectra of $\mathrm{NaSn}_{2}\left(\mathrm{PO}_{4}\right)_{3}$ and NSP glass together with those of crystalline $\mathrm{SnO}$ and $\mathrm{SnO}_{2}$. 
glass suggests that the glass may contain $\mathrm{NaPO}_{3}$ resulting from the reaction

$$
\mathrm{NaSn}_{2}\left(\mathrm{PO}_{4}\right)_{3}+\mathrm{C} \rightarrow \mathrm{Sn}_{2} \mathrm{P}_{2} \mathrm{O}_{7}+\mathrm{NaPO}_{3}+\mathrm{CO}_{2}
$$

The FTIR spectra of the NSP glass and $\mathrm{NaSn}_{2}\left(\mathrm{PO}_{4}\right)_{3}$ together with those of the crystalline $\mathrm{SnO}$ and $\mathrm{SnO}_{2}$ are shown in figure 7. Presence of features arising from both $\mathrm{Sn}^{4+}$ and $\mathrm{Sn}^{2+}$ can be seen in the spectra of NSP glass. $\mathrm{Na}^{+}$ion cage vibration band is also expected in this region (Exarhos and Risen 1972; Nelson and Exarhos 1979) but it is mixed with the bands arising from both $\mathrm{SnO}$ and $\mathrm{SnO}_{2}$ in this region. The shoulder near $330 \mathrm{~cm}^{-1}$ in the spectra of NSP glass which is found in $\mathrm{SnO}$ also suggests the presence of 4-coordinated $\mathrm{Sn}^{2+}$ in the NSP glass.

Fluorescence of $\mathrm{Sn}^{2+}$ in glasses is well-known (Parke and Webb 1971; Reisfeld et al 1975). The excitation as well as the emission wavelengths of $\mathrm{Sn}^{2+}$ are greatly affected by the nature of the crystalline or glassy matrix (Mooney 1959, 1960; Parke and Webb 1971; Reisfeld et al 1975; Mărculescu et al 1980; Donker et al 1989). The NSP glass is found to fluoresce with a somewhat weak green emission. The excitation and emission spectra of NSP glass are shown in figure 8. The emission spectrum is a broad one with maximum intensity near $515 \mathrm{~nm}$. The excitation spectrum has a strong band centred near $345 \mathrm{~nm}$ and a weak one near $280 \mathrm{~nm}$. It is seen that the shape as well as the position of the emission and excitation bands are considerably different from those reported for other $\mathrm{Sn}^{2+}$ containing glasses at doping concentrations of $1 \mathrm{wt} \%$ (Parke and Webb 1971; Reisfeld et al 1975). The excitation bands may be assigned to transitions from the ${ }^{1} S_{0}$ ground state to the crystal field split levels of the ${ }^{3} P_{1}$ excited state of the $\mathrm{Sn}^{2+}$ ion which is an $s^{2}$ (Mooney 1959, 1960; Donker et al 1989). The position of the excitation maximum indicates the presence of $\mathrm{Sn}^{2+}$ in octahedral coordination (Mooney 1959, 1960; Donker et al 1989).

The spectroscopic results (IR, FTIR and fluorescence) indicate that in the NSP glass, tin is present in both $\mathrm{Sn}^{2+}$ and $\mathrm{Sn}^{4+}$ oxidation states and in both 4- and 6-coordinations. Tin has been found to exist only in $2+$ oxidation state in several phosphate glasses from Mössbauer studies (Evtrop'ev et al 1970). The stabilization of $\mathrm{Sn}^{4+}$ in NSP glasses which was prepared starting from $\mathrm{NaSn}_{2}\left(\mathrm{PO}_{4}\right)_{3}$ could arise from the fact that only a particular ratio of $\mathrm{Sn}^{4+}$ to $\mathrm{Sn}^{2+}$ can exist in the melts (which is also temperature-dependent). The melting conditions reduce $\mathrm{Sn}^{4+}$ to $\mathrm{Sn}^{2+}$ till such a ratio is attained. In fact such equilibrations have been shown to exist in tin containing silicate and borate glasses (Bartenev et al 1976; Dannheim et al 1976; Lechtenböhmer and

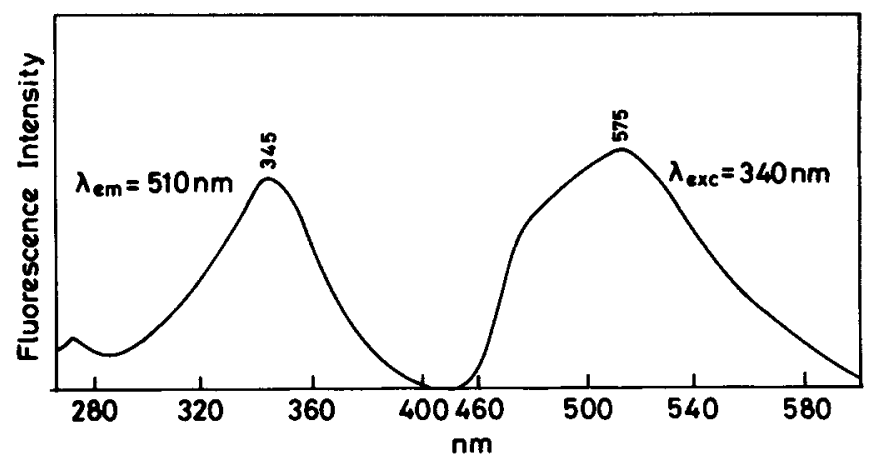

Figure 8. Fluorescence excitation and emission spectra of NSP glass. 
Müller-Warmuth 1982). Attempts at quantitative estimation of $\mathrm{Sn}^{4+}$ and $\mathrm{Sn}^{2+}$ did not prove successful. Chemical routes for the estimation could not be employed because the glasses are insoluble in water. X-ray photoemission spectroscopy (XPS) also was not successful due to the closeness of the core electron binding energies of $\mathrm{Sn}^{4+}$ and $\mathrm{Sn}^{2+}$. $\mathrm{NSP}+\mathrm{SnO}_{2}$ glasses suggest that glass can be made with up to $16 \%$ of tin in the $\mathrm{Sn}^{4+}$ state.

\section{Conclusion}

Tin in pyrophosphate glasses has a tendency to be present largely in $\mathrm{Sn}^{2+}$ state but a substantial proportion of tin can be stabilized as $\mathrm{Sn}^{4+}$ in phosphate glass. Tin ions may be present in both four- and six-coordinated sites.

\section{Acknowledgement}

K C S thanks the University Grants Commission, New Delhi for a fellowship.

\section{References}

Alamo J and Roy R 1986 J. Mater. Sci. 21444

Ananthraj S 1991 Studies on pyrophosphate glasses, Ph D thesis, Indian Institute of Science, Bangalore

Ananthraj S, Varma K B R and Rao K J 1986 Mater. Res. Bull. 211369

Bartenev G M, Magomedov G M, Tsyganov A D and Zelenev Yu V 1976 Sov. J. Glass. Phys. Chem. 2112

Corbridge D E C and Lowe E J 1954 J. Chem. Soc. 493

Damodaran K V, Selvaraj U and Rao K J 1988 Mater. Res. Bull. 23151

Dannheim H, Oel H J and Tomandl G 1976 Glastech. Ber. 49170

Donker H, Smit W M A and Blasse G 1989 Phys. Status Solidi B156 K93

Evtrop'ev K S, Bezrodnyi V G, Seregin P P and Shipatove V T 1970 Inorg. Mater., Consultants Bur. Transl. 6685

Exarhos G J and Risen Jr. W M 1972 Solid State Commun. 11755

Goodenough J B, Hong H Y-P and Kafalas J A 1976 Mater. Res. Bull. 11203

Lechtenböhmer A, Mosel B, Müller-Warmuth W and Dutz H 1982 Glastech. Ber. 55161

Mărculescu L, Ghită C and Mihut L 1980 Phys. Status Solidi $\mathbf{A 6 1} 497$.

Mooney R W 1959 J. Electrochem. Soc. 106955

Mooney R W 1960 J. Electrochem. Soc. 107100

Musić S M, Bajs Z, Furić K and Mohaček V 1991 J. Mater. Sci. Lett. 10889

Nelson BN and Exarhos G J 1979 J. Chem. Phys. 712739

Osaka A, Takahashi K and Ikeda M 1984 J. Mater. Sci. Lett. 336

Parke S and Webb R S 1971 J. Phys. D4 825

Reisfeld R, Boehm L and Barnett B 1975 J. Solid State Chem. 15140

Selvaraj U and Rao K J 1988 J. Non-Cryst. Solids 104300

Sobha K C and Rao K J 1995 Spectrochim. Acta A (submitted)

Tick P A 1984 Phys. Chem. Glasses 25(6) 149

Wyckoff R W G 1971 Crystal structures (New York: Wiley) vol. 1 